\title{
The Use of an Interactive Multimedia Thermodynamics to Improve Conceptual Mastery of Physics Prospective Teachers
}

\author{
A. Hakim ${ }^{1}$, A. Masruhim ${ }^{2}$, R. Qadar ${ }^{3}$, M. Syam ${ }^{4}$ \\ ${ }^{1,2,3,4}$ Faculty of Teacher Training and Education, Universitas Mulawarman, Samarinda, Indonesia \\ abdul.hakim@fkip.unmul.ac.id
}

\begin{abstract}
This study aimed to determine the improve of conceptual mastery of thermodynamics as result of the implementation of the interactive multimedia thermodynamics. Research method used a quasi-experiment with control group pretest-posttest design. The research subject was students as experimental group and control group of physics prospective teachers of the fourth semester, in one of the state university in East Kalimantan. The research instrument used multiple choice test embedded conceptual mastery of thermodynamics. Data analyzed with the differences of two averages. The result showed that after the implementation of interactive multimedia improved of conceptual mastery of physics prospective teachers quite effectively. These results indicated that the interactive multimedia improve the conceptual mastery of physics prospective teachers.
\end{abstract}

Keywords-interactive multimedia; thermodynamics; conceptual mastery

\section{INTRODUCTION}

Various applications thermodynamics play an important role in human life. The engineer uses the principle of thermodynamics in their studies to design variety of energy system as required human needs, such as power generation, air conditioner system, jet and automobile engines. The engineers also working to improve of design and enhance the performance that can be measured by variety of factors such as the increase in output of desired product, a reduction in the consumption of natural resources are dwindling, total cost reduction, or a negative impact on the environment. At the global situation, where the acceleration changes occurs in all sectors, then one of the most urgent resources must be prepared to face the world of work is the human resources e.i. teachers. For this reason it should be developed to organize a good learning process that will produce quality graduates.

However, the problem lies in the non-mathematical materials or concepts of thermodynamics, the large number of formulas, abstract concepts, and that it is based on principles and states processes and cycles. These aspects affect students' ability in understanding the materials; sometimes even cause frustration in building their mental model, trigger boredom, and eventually negatively impact their learning outcomes. A number of research results in relation to the difficulties experienced by students in understanding thermodynamic concepts are, among others, as follows: [4] reported that students were not able to integrate thermodynamics concepts into complex phenomena. [6] found that students experienced difficulties in visualizing abstract concepts. Students also had difficulties in applying $\mathrm{p}-\mathrm{V}$ diagram to solve problems [10]. In addition, [11] discovered that students misinterpreted the laws of ideal gases. Hence, efforts of improving the teaching and learning process should be made by actively involving students in building their knowledge and understanding through the use of information technology as instructional media in the form of thermodynamics interactive media so that students, in this case physics prospective teachers, can grow their conceptual mastery of thermodynamics.

Various pieces of research pertaining to the use of interactive multimedia in teaching and learning show that interactive multimedia is considered to be beneficial in facilitating improvement in college students' conceptual mastery and science generic skills. Integration of computer animation into teaching and learning was proven to be effective in helping students increase their understanding of various physics concepts [1]. Interactive multimedia can visualize and simplify the abstract concepts of thermodynamics, such as enthalpy and entropy. [12] reported that abstract concepts such as laws of gases are more easily understood when taught using multimedia. [7] revealed that the use of interactive simulation would improve students' mental model. On the same note, [9] said that interactive software assisted students in understanding abstract concepts in the concept of quantum mechanics. [2] reported that teaching and learning with intranet web was effective to improve the mastery of the concepts of work, energy, and power. Therefore, the purpose of applying interactive multimedia thermodynamic in this research is to improve conceptual mastery of physics prospective teacher.

\section{METHOD}

This research is quasi experiment with control group pretest-posttest design. In this design there are two groups, namely experimental group $(n=34)$ and control group $(n=33)$. The experimental group received learning using interactive multimedia thermodynamics and the control group gained 
conventional learning. The two groups performed pretest and posttest conceptual mastery of thermodynamics in the form of multiple choices questions. The result of qualitative question validity analysis by three expert shows that the question of conceptual mastery of thermodynamics is valid to be used and the result of quantitative validity show significant result. The reliability of the question show that high internal consistency (0.79). The data of the two groups were analyzed using the mean difference test and normalized gain scores $\langle\mathrm{g}>$. Level of significance of two-averaging test used effect size calculation (d).

\section{RESULTS OF RESEARCH}

Thermodynamics Interactive Multimedia developed in this research includes the following concepts: the basic concepts of thermodynamics, energy and the first law of thermodynamics, properties of pure substances, behavior of ideal gases, the second law of thermodynamics, and Carnot's cycle. The materials of the Thermodynamics Interactive Multimedia are equipped with pictures, graphs, mathematical modelling, and interactive simulations. The supplementary materials assist students in their thinking activities in order to understand the concepts of thermodynamics well. The Thermodynamics Interactive Multimedia can be operated using windows-based computers. The program is supported by macromedia flash. Figure 1 shows several examples of the presentations of interactive multimedia developed in this research.

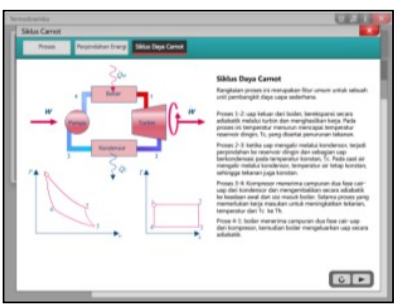

(a)

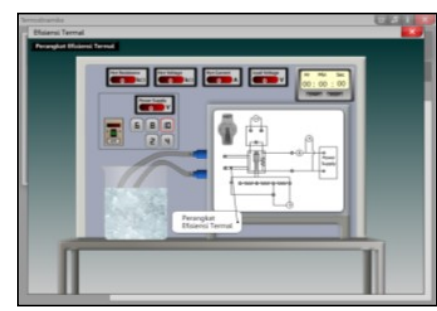

(b)
Figure 1. Examples of the Thermodynamics Interactive Multimedia presentations for the material of the second law of thermodynamics: (a) animation; (b) virtual experiment.

The development of thermodynamics interactive multimedia in this research was conducted using the $3 \mathrm{D}-\mathrm{E}$ planning model consisting of Decide, Design, Develop, and Evaluate [5]. At the phase of "Decide," the stages taken included doing literature review, determining instructional goals, deciding themes or areas for the Thermodynamics Interactive Multimedia to be made, and determining prerequisite skills of using computer that should be possessed by the prospective teachers. The "Design" phase comprised of the making of flowcharts and storyboards to be made the basis in making program software. At the "Develop" phase, the actions carried out were making the required components of the Thermodynamics Interactive Multimedia, such as making graphs, making programs, and testing the programs. Next, the "Evaluate" phase was the phase to make sure that the finished Thermodynamics Interactive Multimedia was aligned to the formulated goals and the prevailing standards; hence, assessment of the feasibility of the Thermodynamics
Interactive Multimedia was done by six experts (three physics experts and three instructional multimedia experts). The aspects of Thermodynamics Interactive Multimedia assessed included materials (presentation and content) and multimedia (technical aspect, language, and graphs). Subsequently, limited trials were carried out twice to build user feedback.

To determine the success of thermodynamics teaching and learning based on interactive multimedia in terms of the prospective teachers' conceptual mastery, the normalized gains $<\mathrm{g}>$ of the experimental and control group were analyzed. The mean normalized gains $<\mathrm{g}>$ for each concept thermodynamics are presented in Figure 2.

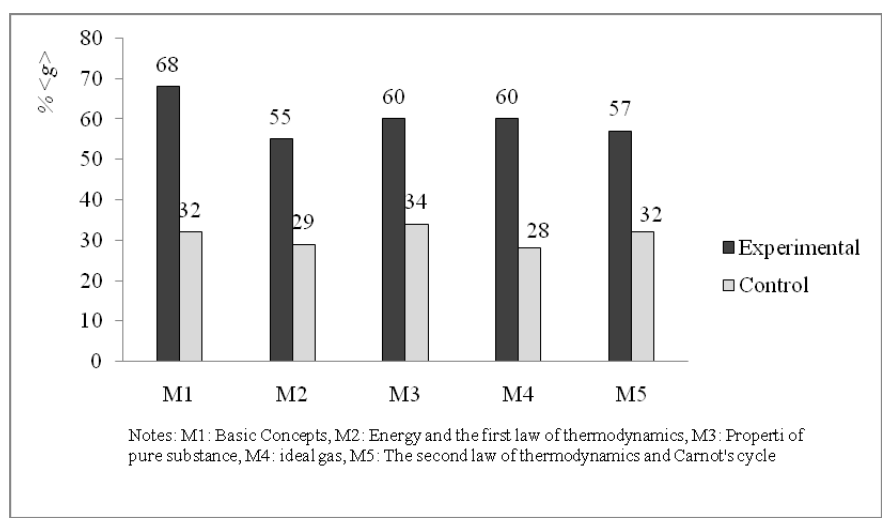

Figure 2. The mean normalized gains $<\mathrm{g}>$ for each concept thermodynamics.

The mean difference of the normalized gains $<\mathrm{g}>$ in Figure 2 show differences in the level of difficulties experienced by the physics prospective teachers in understanding each of the thermodynamics concepts.

\section{DISCUSSION}

The normalized gains $<\mathrm{g}>$ of basic concepts of thermodynamics for the experimental group and control group were normally distributed. The normalized gains $\langle\mathrm{g}\rangle$ were then analyzed parametrically using independent sample $t$-test at 0.05 significance level and critical significance $p>0.05$. The results of analysis of $t$-test $\left(t_{\text {count }}=41.821, \mathrm{Sig} .=0.000\right)$ indicate that the average normalized gains $\langle\mathrm{g}\rangle$ of basic concepts of thermodynamics for the two groups differed significantly with an effect size $(d=1.27)$ categorized as high. This finding means that the teaching and learning of thermodynamics with interactive multimedia could significantly improve the basic concepts of thermodynamics.

The normalized gains $<\mathrm{g}>$ of energy and the first law of thermodynamics for the experimental group and control group were not normally distributed. The normalized gains were then analyzed non-parametrically using Mann-Whitney (independent sample test). The results of analysis of $Z$-test. The results of analysis of $Z$-test $\left(Z_{\text {count }}=-5.466\right.$, Sig. $\left.=0.000\right)$ demonstrate that the normalized gains of both groups were significantly different, with an effect size $(d=1.53)$ at the high category. The results demonstrate that the teaching and learning of thermodynamics with interactive multimedia could 
significantly improve energy and the first law of thermodynamics concepts.

The normalized gains $<\mathrm{g}>$ of properties of pure substances for the experimental group and control group were not normally distributed. The normalized gains were then analyzed non-parametrically using Mann-Whitney (independent sample test). The results of analysis of $Z$-test $\left(Z_{\text {count }}=-4.026\right.$, Sig. $\left.=0.000\right)$ demonstrate that the normalized gain scores of properties of pure substances for both groups were significantly different, with an effect size $(d=1.04)$ at the high category. The result demonstrates that the teaching and learning of thermodynamics with interactive multimedia could significantly improve the properties of pure substances concepts.

The normalized gains $<\mathrm{g}>$ of ideal gases for the experimental group and control group were not normally distributed. The normalized gains were then analyzed nonparametrically using Mann-Whitney (independent sample test). The results of analysis of $Z$-test $\left(Z_{\text {count }}=-4.650\right.$, Sig. $=0.000)$ demonstrate that the normalized gain scores of the ideal gases for both groups were significantly different, with an effect size $(d=1.54)$ at the high category. The result demonstrates that the teaching and learning of thermodynamics with interactive multimedia could significantly improve the ideal gases concepts.

The normalized gains $<\mathrm{g}>$ of the second law of thermodynamics, and Carnot's cycle for the experimental group and control group were not normally distributed. The normalized gains were then analyzed non-parametrically using Mann-Whitney (independent sample test). The results of analysis of $Z$-test $\left(Z_{\text {count }}=-4.34\right.$, Sig. $\left.=0.000\right)$ demonstrate that the normalized gain scores of the second law of thermodynamics, and Carnot's cycle for both groups were significantly different, with an effect size $(d=1.25)$ at the high category. The result demonstrates that the teaching and learning of thermodynamics with interactive multimedia could significantly improve the second law of thermodynamics, and Carnot's cycle concepts.

Results of data analysis show that the increased average normalized gain $<\mathrm{g}>$ of the conceptual mastery of thermodynamics of the experimental group was greater than that of the control group. The improvement in conceptual mastery of thermodynamics is inseparable from the role of the Thermodynamics Interactive Multimedia used in the experimental group.

The prospective teachers sharpened their understanding thermodynamics process, behavior of ideal gases, Carnot's cycle, and heat engines through the menus of materials and animations; for example, pressure $p, T$ for temperature, and Carnot's cycle. In addition, through virtual experiment activities, the prospective teachers were trained to use symbolic language, such as using symbols to identify various variables. With these various activities, the students were trained to use their understanding; hence, the conceptual mastery of thermodynamics of the experimental group was greater than that of the control group.
Various simulations presented systematically trained students to build a coherent conceptual understanding; for example, the addition of heat to a system and the changes occurring to the system. In addition, the efforts of improving their understanding concepts require a series of systematic exploratory activities. The inquiry approach in the activity of virtual experiment in the interactive multimedia can help prospective teachers do exploratory activities systematically. This claim is in line with the argument of [8] that dynamic multimedia can facilitate students to think systematically in accordance with the order of events based on the regularity of phenomena or symptoms so that students can understand why something happens and what effects take place. [10] stated that teaching and learning aided by computer with animations and simulations in the classroom gives an alternative to students to understand various alternatives to understand concepts through visualization of abstract concepts and graphic representation.

\section{CONCLUSION}

Based on the results previously explained, the Thermodynamics Interactive Multimedia developed in this research is appropriate to be used in the teaching and learning of thermodynamics. The teaching and learning with interactive multimedia was effective in improving the physics prospective teachers' conceptual mastery of thermodynamics compared to the conventional teaching and learning. Finding of the study support the fact that interactive multimedia may be used as an alternative instructional tool. Through animations and simulations (virtual experiment) teachers can easily demonstrate the law, concept, and processes in thermodynamics to their student.

\section{REFERENCES}

[1] A. Kohnle, D. Cassettari, T. J. Edwards, C. Ferguson, A. D. Gillies, C. A. Hooley, and B. D. Siclair, "A new Multimedia resource for teaching quantum mechanics concepts," American Journal of Physics, pp. 80(2), 148-153, February 2012.

[2] A. Doyan, and I. K. Y, "Developing Physics Intranet Web to Improve Vocational High School Students' Conceptual Mastery and Problem Solving). Jurnal Pendidikan Fisika Indonesia, vol. 10(2), pp. 117-127, January 2014.

[3] B. G. Dega, J. Kriek, and T. F. Mogese, "Conceptual change in electricity andmagnetism using simulations: A comparison of cognitive perturbation andcognitive conflict," Journal of Research in Science Teaching, vol. 50(6), pp. 677-698, August 2013.

[4] E. L. Lewis, J. L. Stern, and M. C. Linn, “ The Effect of Computer Simulation on Introductory Thermodynamics Understanding," Education Technology Journal, vol. 33, pp. 45-58. January 1993.

[5] K. S. Ivers, and A. E. Barron, A. E, "Multimedia Projects in Education: Designing, Producing, and Assessing. American: United States of America, 2002.

[6] M. Huang, and K. Gramoll, "Online Interactive Multimedia for Engineering Thermodynamics," Proceeding of ASEE Annual Conference and Exposition. Utah, pp. 10661-10671, June 2004.

[7] P. Junglas, P, "Simulation Programs for Teaching Thermodynamics," UIEE Global J. of Engng. Edu. Poland, vol. 10, pp. 175-180, September 2006.

[8] R. Lowe, "Beyond "eye-candy": Improving Learning with animation," Retrieved 2 October 2015 from http://auc.Uow.edu.au/conf01/pdf. 2001. 
[9] S. B. McKagan, M. Perkins, C. Dubson, S. Malley, R. Reid, LeMaster, and C. E. Wiemna, "Developing and Researching PhET Simulation for Teaching Quantum Mechanics," Physics Education Technology. http://www.colorado.edu/iSTEM/pdfs/QMsims.pdf. 2008.

[10] V. D. Kulkarni, and P. S. Tambade, "Enhancing the Learning of Thermodynamics using Computer Assisted Instructions at Undergraduate Level,” Eurasian J. Phys. \& Chem. Edu., pp. 5(1), 2-10. August 2013.
[11] W. Christensen, D. Meltzer, and C. Ogilivie, “ Students' ideas regarding entropy and the second law of thermodynamics in an introductory physics course," American Journal of Physics, vol. 77(10), pp. 907-917, October, 2009.

[12] X. Liu, "Effects of Combined Hands-on Laboratory and Computer Modeling on Student Learning of Gas Laws: A quasi-experimental study," Journal of Science Education and Technology, vol. 15, pp. 89100, March 2006. 